\title{
Factors Influencing Students' Attitude towards HIV/AIDS in a Public University, Malaysia
}

\author{
Rozina Rahnama \\ Department of Community Health \\ Faculty of Medicine and Health Sciences, Universiti Putra Malaysia \\ 43400 Serdang, Selangor, Malaysia \\ E-mail: rahnamarozina@yahoo.com \\ Lekhraj Rampal (Corresponding Author) \\ Department of Community Health, Faculty of Medicine and Health Science \\ Universiti Putra Malaysia, 43400 Serdang, Selangor, Malaysia \\ Tel: 603-8947-2411 E-mail: rampal@medic.upm.edu.my \\ Munn-Sann Lye \\ Department of Community Health, Faculty of Medicine and Health Sciences \\ Universiti Putra Malaysia, 43400 Serdang, Selangor, Malaysia \\ E-mail: mslye@medic.upm.edu.my \\ Hejar Abdul Rahman \\ Department of Community Health, Faculty of Medicine and Health Sciences \\ Universiti Putra Malaysia, 43400 Serdang, Selangor, Malaysia \\ E-mail: hejar@medic.upm.edu.my
}

Received: September 25, 2010 Accepted: October 12, 2010 doi:10.5539/gjhs.v3n1p128

\begin{abstract}
Acquired Immunodeficiency Syndrome has remained one of the priority global public health challenges. The aim of this cross-sectional study was to determine the attitudes related to HIV/AIDS among students in a public university in Malaysia. The students were selected based on a two-stage probability proportionate to size random sampling method. Data was analyzed using SPSS version 17. Out of the 1773 respondents, $57.3 \%$ were female and the mean age was 22.5 years. The results showed that only $19.5 \%$ stated that they will inform their partners or family if diagnosed positive for HIV infection and $43 \%$ were willing to care for an HIV infected person in their own house. The overall mean attitude score was 24.1. Knowledge was significantly associated with the attitude towards HIV/AIDS among students. However, age, educational level, marital status, place of residence was not associated with the attitude towards HIV/AIDS among students.
\end{abstract}

Keywords: Attitude, HIV/AIDS, University Students, Malaysia

\section{Introduction}

Ever since its onset, the Human Immuno-deficiency Virus (HIV) pandemic has been a growing global threat to mankind. It has been increasing at an alarming rate since the first cases were reported in the early 1980s. It causes significant morbidity and mortality in human societies throughout the world (WHO, 2004), reduces the life expectancy of infected persons and increases the number of orphaned children. It also creates turbulence in health care systems and contributes to economic insecurity, potentially leading to political instability (Sowell, 2004). The number of people living with HIV worldwide continued to increase in 2008 , reaching an estimated 33.4 million [31.1 million-35.8 million]. The total number of people living with the virus in 2008 was more than 
$20 \%$ higher than in 2000 , and the prevalence was threefold higher than in 1990 . However, globally the spread of HIV appears to have peaked in 1996, with 3.5 million [3.2 million-3.8 million] new HIV infections. In 2008, there were 2,690,000 new infections (430,000 children, 920,000 young people and 1,340,000 adults); the estimated number of new HIV infections was approximately 30\% lower than at the epidemic's peak 12 years earlier. However, there were still 1200 children, 2500 young people and 3700 adults newly infected per day (UNAIDS/WHO, 2009 and UNAIDS, 2010).

The second decade of life is a period of experimentation and risk, and many factors increase young persons' vulnerability to HIV during these years of rapid physical and psychosocial development (Ross et al., 2006). These factors include a lack of knowledge about HIV/AIDS, lack of education and life skills, poor access to health services and commodities, early sexual debut, early marriage, sexual coercion. Violence, human trafficking and growing up without parents or other forms of protection from exploitation and abuse also contribute to increased risk. Other most important contributory factors are alcohol and drug abuse. In the HIV/AIDS situation and response analyses studies conducted in Botswana and Western Ethiopia, it has been noted that alcohol, multiple partners, and peer pressure contribute to the spread of HIV infections (Fidzani et al., 1999; Fidzani et al., 2000; Molebatsi \& Mogobe, 2000, 2001; Ntseane \& Ncube, 2001; Seloilwe \& Ntseane, 2001). Previous studies showed that risk factors for the spread of HIV/AIDS among university students are peer pressure, alcohol and drug abuse, unprotected sex and frequent change of sexual partners (Esther, 2005).

In Malaysia between the first detected case in 1986 and 2009, 87,710 men, women and children have been infected with HIV; while 13,394 have died of AIDS (UNAIDS - UNGASS, 2010). The cumulative reported cases of HIV transmission has been predominantly through injecting drug use (70.6 \%), followed by heterosexual intercourse $(16.9 \%)$ and homosexual or bisexual contact $(2.0 \%)$. However, only $55.2 \%$ of new HIV cases in 2009 were attributed to injecting drugs use. Of concern is the fact that new HIV infections amongst women continued to increase from $1.2 \%$ of total new cases in 1990 to $9.0 \%$ in $2002,10.8 \%$ in $2004,15 \%$ in 2006 and to $16 \%$ by December 2007 (Ministry of Health Malaysia/UNICEF, 2008). In 2008, 19\% of new cases were women. The percentage of babies born with HIV remains at relatively low levels - around $1.4 \%$ of new cases in recent years as a result of a Government sponsored prevention program for pregnant women. HIV transmission in Malaysia is predicted to increase through sexual modes of transmission while infections acquired through injecting drug use are expected to plateau in the next few years (UNAIDS- UNGASS, 2010). New HIV infections in the age group of $13-19$ years old increased from $0.85 \%$ in 2004 to $2.0 \%$ in 2008. Ministry of Health (2008) reported that $27 \%$ of new infections are amongst teens and youth aged between 13 to 29 years old. Gender inequity, stigma, discrimination, silence, denial and ignorance fuel the epidemic in Malaysia (UNICEF Malaysia, 2010). Rampal (2007) reported that in a national study carried out in Malaysia in 2004, out of the 18,805 respondents aged 15 years and above, 13,971 (74.3\%) respondents had experienced sex. Amongst the 13,971 respondents who had experienced sex, $38.2 \%$ of them had before the age 20 years. Amongst those who have had sexual intercourse (married or never married), the mean age at first intercourse was 22.7 years (95\% CI 22.6 - 22.7 years) and ranged from 10 years to 49 years. The median age at first intercourse was 22 years. The median age of the respondents at first marriage was lowest amongst the Bumiputra Sarawak (20 years) followed by Bumiputra Sabah (21 years), Malays ( 22 years), Indians ( 23 years), and Chinese ( 25 years). The overall median age at first marriage was 23 years. Amongst those who had never married, $8.9 \%$ reported have had sexual intercourse and the overall mean age at first intercourse was 20 years. Lee et al. (2006) reported that among 4,500 secondary school students aged 12 to 19 years surveyed in Negeri Sembilan Malaysia, $8.3 \%$ of the males compared with $2.9 \%$ of the female had premarital sexual intercourse. Ng and Kamal 2006 observed a gender difference in how adolescents perceived sex, their perception of risk of contracting HIV and AIDS, and attitudes towards condom use. Adolescent sexuality is influenced by many factors such as gender roles, power inequality, culture, social class, peer pressure and access to information.

For planning and implementation of HIV/AIDS education programs among youths, it is essential to know the factors that influence attitudes related to HIV/AIDS among the youth. This paper aims to report on the factors associated with attitudes related to HIV/AIDS among students in a public university in Malaysia. Factors associated with knowledge related to HIV/AIDS prevention has been reported elsewhere.

\section{Material and Methods}

A cross-sectional study was conducted in a Malaysian university with 23,202 registered students. A two-stage simple random sampling technique with probability proportionate to size was used to select four faculties and two institutes out of 15 faculties and seven institutes. Approval was obtained from the University Medical Research Ethics Committee and informed consent was obtained from each student. A pre-tested, standardized, self-administered questionnaire in the Malay and English languages was used to collect the data. It consisted of 
questions related to socio-demographic factors and attitude related to HIV/AIDS. Socio-demographic variables were gender, age, residence, nationality, ethnicity, religion, marital status, educational level, faculty/institute, employment status and family economic status. Attitude was measured by composite score of 7 items using the five-point Likert-scale from 1 for strongly agree to 5 for strongly disagree. A higher attitude score indicated higher positive attitude towards HIV/AIDS. Knowledge was determined using 34 factual questions on HIV/AIDS using 'True' or 'False' or 'Don't Know' response. A correct answer was scored 1, an incorrect answer and 'Don't Know' responses were scored 0 for questions related to knowledge. The minimum and maximum scores for total knowledge scores were 0 and 34 respectively.

Data was analyzed using Statistical Package of Social Sciences (SPSS) version 17. Total attitude scores, quartiles and percentiles were computed. Content validity was evaluated by a committee. The standardized Cronbach's alpha reliability coefficient ranged from 0.61 to 0.82 . Continuous data checked using Kolmogorov-Smirnov test showed normal distribution. Independent sample t-test (for two groups) was used to compare means between two groups. Multiple linear regression was used to determine the predictors of attitudes towards HIV/AIDS. The level of significance was set at 0.05 .

\section{Results}

\subsection{Response Rate}

Out of the total 1920 students, 1773 agreed to participate in the study, giving a response rate of $92.3 \%$.

\subsection{Socio-demographic characteristics of Respondents}

Table 1 shows the socio-demographic characteristics of respondents. Out of 1773 respondents, slightly over half $(57.3 \%)$ were female. The overall mean age of respondents was 22.5 years $(95 \%$ CI $22.3-22.7)$ and ranged from 18.0 years to 52.0 years. The mean age and standard deviation of male respondents ( $23.2 \pm 5.4$ years) was significantly different as compared to $(22.0 \pm 3.7$ years $)$ for the females $(\mathrm{t}=5.5, \mathrm{df}=1732$ and $p=0.001)$. Out of 1773 respondents, $93.6 \%$ were Malaysians. Slightly over half $(52.5 \%)$ were Malays, followed by Chinese (34.9\%), Indians (4.6 \%) and Bumiputras of Sabah and Sarawak (1.9\%). There were $6.1 \%$ foreign students.

\subsection{Attitude towards HIV/AIDS}

Table 2 shows the distribution of the respondents' attitude on HIV/AIDS - related items. The overall mean and standard deviation of attitude score was $24.1( \pm 3.1)$ with a median of 24.0 and a range of $11.0-34.0$, and the inter quartile range was 4.0. However, only $19.5 \%$ of all the students stated that they will inform their partners or family if they were diagnosed positive for HIV infection. In this study, only $43 \%$ were willing to care for HIV infected person in their own house. About $42.3 \%$ of respondents believed that an infected teacher should not be allowed to continue teaching in school. However, $73.7 \%$ respondents agreed that a child who is infected with HIV can go to a normal school. Majority $(81.8 \%)$ of respondents stated that there should be employment opportunity for HIV infected people. Majority (93\%) approved screening for HIV as a prerequisite for marriage and they agreed that it should be compulsory before getting married and $91.6 \%$ believed that pre-marital testing for HIV can protect men and women from HIV infection. It is worth noting that about $82.3 \%$ of the respondents believed use of condoms as a means to prevent transmission of HIV.

Multiple linear regression analysis showed that knowledge was associated with attitude regarding HIV/AIDS among students. However age, gender, ethnicity, and marital status were not associated with attitude (Table 3).

\section{Discussion}

Stigmatization and lack of empathy is still a big problem among university students as shown in this study where only $19.5 \%$ of all the students stated that they will inform their partners or family if diagnosed positive for HIV infection and only $43 \%$ were willing to care for an HIV infected person in their own house. This attitude could pose a serious threat to prevention and students need to be educated to change their attitude. However, majority of them (93\%) approved screening for HIV as a prerequisite for marriage and they agreed to be compulsory before getting married and $91.6 \%$ believed that pre-marital testing for HIV can protect men and women from HIV infection. These findings are comparable with the findings from a community-based study conducted by Negash et al. (2003) and another study by Andargie et al. in 2007 in Ethiopia. Lee et al. (2006) reported that the percentage of premarital sexual activity seems to have increased in Malaysia over the years. This can be due to rapid modernization and social changes in the country. Despite the stigma that is present in the culture with regard to sexuality, this finding of somewhat positive attitudes toward safer sex behavior could be an indication of the changing attitudes of younger people toward sexuality and safer sex behaviors. With regard to HIV testing behavior, there were very low levels of HIV testing among the students. Despite changing attitudes among the younger society, stigma may still remain regarding obtaining an HIV test. Further, it was suggested by Fisher 
and Fisher (2000) that college students tend to erroneously believe that it is easy to detect risky partners on the basis of how they dress or how they act, and without knowing their partner's HIV status, feel that AIDS prevention is unnecessary. Reports of condom use in this sample were low, which suggested that there is a tendency for humans to have unrealistic optimism about their susceptibility to illness and to feel that diseases such as AIDS happen only to others. Hence, young adults in this study particularly may not believe it is crucial to always practice safer sex. Educational efforts need to be targeted at those who are most misinformed to meet the needs of different populations such as particular age groups, those in different geographical locations, and different ethnic groups. It is worth noting that about $1456(82.3 \%)$ of the respondents believed the use of condom as a means of preventing transmission of HIV. In line with this, relationship between risky sexual behaviors among students with their condom utilization has been reported (Lee et al., 2006).

A key challenge for HIV/AIDS prevention education programs will be to apply methods that result in rapid enhancement in knowledge and attitudes regarding basic practices such as condom use and limiting sexual partners. However, it is necessary to take into consideration the psycho-social and cultural factors that affect young people and their ability to harmonise what they know about safer sex with their cultural beliefs involving gender and power. Attaining greater effectiveness in prevention depends less on the content of educational messages than on the process which is used to motivate young adults in changing their culture. Fortunately, the studies on peer counseling shows that peer have a powerful influence on the students themselves (Vaughan et al., 2000).

This study has several methodological strengths. The sample is relatively large, and was drawn from four faculties and two institutes of the university by using two stage random sampling method that represent the overall attitude among students in university. However, the use of a one-off questionnaire as a measurement instrument is not adequate to measure attitudes in terms of HIV/AIDS and that future studies should look into different measurement methods. Another limitation of this study is that the results may not be generalisable to all university students in Malaysia.

In conclusion, stigmatization and lack of empathy is still a big problem among university students. Only $19.5 \%$ of all the students stated that they will inform their partners or family if diagnosed positive for HIV infection and only $43 \%$ were willing to care for an HIV infected person in their own house. It is recommended that a peer educational program on HIV/AIDS prevention be implemented in schools and communication through television, radio and print media be further enhanced.

\section{Acknowledgement}

Our thanks are due to Professor Dr Norlijah Othman, Dean, Faculty of Medicine and Health Sciences, University Putra Malaysia for giving permission to publish this paper and the students who participated in this study.

\section{References}

Andargie G, Kassu A, Moges F, Kebede Y, Gedefaw M, Wale F, Alem A, Andualem B, Adungna S. (2007). Low prevalence of HIV infection, and knowledge, attitude and practice on HIV/AIDS among high school students in Gondar, Northwest Ethiopia. Ethiop.J.Health Dev; 21(2): 179-182.

Esther S. (2005). Factors That Influence the Spread of HIV/AIDS among Students of the University of Botswana. Journal of the Association of Nurses in AIDS Care, 16 (3): 3-10.

Fidzani, N. H., Ntseane, D., \& Seloilwe, E. S. (2000). HIV/AIDS in the North East District: Situation and response analyses. Gaborone, Botswana: AIDS/Sexually Transmitted Disease Unit and United Nations Development Program.

Fidzani, N. H., Ntseane, D., Seloilwe, E. S., \& Nthomang, K. (1999). HIV/AIDS in the South East District: Situation and response analyses. Gaborone, Botswana: AIDS/Sexually Transmitted Disease Unit and United Nations Development Program.

Fisher J D, Fisher WA. (2000). Theoretical approaches to individual-level change in HIV risk behavior. In J. L. Peterson \& R. J. DiClemente (Eds.), Handbook of HIV Prevention New York: Plenum. 3-55.

Lee L.K., Chen P.CY, Lee KK, Kaur J. (2006). Premarital sexual intercourse among adolescents in Malaysia: a cross-sectional Malaysian school survey. Singapore Med J, 47(6):476-481.

Lekhraj Rampal. (2007). Sexual Practices in Malaysia. Proceedings on Scientific Meeting on Sexuality in Medicine. Faculty of Medicine and Health Sciences UPM and Malaysian Healthy Aging Society.

Ministry of Health \& UNICEF. Ministry of Health \& UNICEF Report 2008: Women and Girls Confronting HIV and AIDS in Malaysia, 2008 UNICEF. 
Ministry of Health Malaysia and World Health Organisation. (2009). National Consensus Workshop on Estimation and Projection of the Malaysian HIV Epidemic. Revised version 20th March 2010.

Ministry of Health Malaysia. (2010). Statistics of HIV AIDS in Malaysia (1986 - 2009).

Molebatsi, C. O., \& Mogobe, K. D. (2000). HIV/AIDS in the North West District: Situation and response analyses. Gaborone, Botswana: AIDS/Sexually Transmitted Disease Unit and United Nations Development Program.

Molebatsi, C. O., \& Mogobe, K. D. (2001). HIV/AIDS in the North West District: Situation and responses analyses. Gaborone, Botswana: AIDS/Sexually Transmitted Disease Unit and United Nations Development Program.

Negash Y, Gebre B, Benti D, Bejiga M. (2003). A community based study on knowledge, attitude and practice (KAP) on HIV/AIDS in Gambella town, Western Ethiopia. Ethiopian Journal of Health Development, 17(3): 205-213

Ng CJ, Kamal SF. (2006). Bridging the gap between adolescent sexuality and HIV risk: the urban Malaysian perspective. Singapore Med J 2006, 47:482-90.

Ntseane, D., \& Ncube, E. M. (2001). HIV/AIDS in the North West District: Situation and response analyses. Gaborone, Botswana: AIDS/Sexually Transmitted Disease Unit and United Nations Development Program.

Ross D.A., Dick B et al. (2006). Preventing HIV/AIDS in young people: a systematic review of the evidence from developing countries. UNAIDS Inter-agency Task Team on Young People.

Seloilwe, E. S., \& Ntseane, P. (2001). HIV/AIDS in the City of Francistown: Situation and response analyses. Gaborone, Botswana: AIDS/Sexually Transmitted Disease Unit and United Nations Development Program.

Sowell RL. (2004). Time to make a theme the reality. Journal of the Association of Nurses in AIDS Care 2004; 15(3): 21-22.

UNAIDS. (2010). Malaysia UNGASS Country Progress Report January 2008 - December 2009.

UNAIDS. (2010). UNAIDS Outlook report 2010. UNAIDS. [Online]: www.unaids.org/outlook/OutlookReport.

UNAIDS/WHO. (2009). AIDS epidemic update: December 2009. Geneva: The Joint United Nations Program on HIV/AIDS and the World Health Organization.

UNICEF, Malaysia. (2010). Challenging HIV and AIDS: HIV and AIDS in 2008 www.unicef.org/Malaysia/hiv_aids.html.

Vaughan PW, Rogers EM, Singhal A, Swalehe RM. (2000). Entertainment-education and HIV/AIDS prevention: a field experiment in Tanzania. $J$ Health Commun, 5(Suppl):81-100.

WHO. The World Health Report. (2004). Changing history. Bulletin of the World Health Organization 2004; 82(6): 477-478. 
Table 1. Demographic characteristics of the respondents

\begin{tabular}{|c|c|c|}
\hline Characteristics & Frequency & $(\%)$ \\
\hline $\begin{array}{l}\text { Gender } \\
\text { Male } \\
\text { Female } \\
\text { Total }\end{array}$ & $\begin{array}{l}756 \\
1016 \\
1772 \\
\end{array}$ & $\begin{array}{l}42.7 \\
57.3 \\
100.0\end{array}$ \\
\hline $\begin{array}{l}\text { Age Group (years) } \\
<20 \\
20-21 \\
22-23 \\
>24 \\
\text { Total }\end{array}$ & $\begin{array}{l}578 \\
360 \\
532 \\
294 \\
1764 \\
\end{array}$ & $\begin{array}{l}33.3 \\
20.8 \\
29.0 \\
16.9 \\
100.0\end{array}$ \\
\hline $\begin{array}{l}\text { Gender } \\
\text { Male } \\
\text { Female } \\
\text { Total } \\
\end{array}$ & $\begin{array}{l}756 \\
1016 \\
1772 \\
\end{array}$ & $\begin{array}{l}42.7 \\
57.3 \\
100.0\end{array}$ \\
\hline $\begin{array}{l}\text { Nationality } \\
\text { Malaysian } \\
\text { Foreigners } \\
\text { Total } \\
\end{array}$ & $\begin{array}{l}1663 \\
108 \\
1771 \\
\end{array}$ & $\begin{array}{l}93.9 \\
6.1 \\
100.0 \\
\end{array}$ \\
\hline $\begin{array}{l}\text { Residence } \\
\text { Urban } \\
\text { Rural } \\
\text { Total }\end{array}$ & $\begin{array}{l}1188 \\
574 \\
1762 \\
\end{array}$ & $\begin{array}{l}67.4 \\
32.6 \\
100.0\end{array}$ \\
\hline $\begin{array}{l}\text { Ethnicity } \\
\text { Malay } \\
\text { Chinese } \\
\text { Indian } \\
\text { Bumiputra Sabah and Sarawak } \\
\text { Foreigner } \\
\text { Total } \\
\end{array}$ & $\begin{array}{l}929 \\
618 \\
82 \\
34 \\
108 \\
1771 \\
\end{array}$ & $\begin{array}{l}52.5 \\
34.9 \\
4.6 \\
1.9 \\
6.1 \\
100.0 \\
\end{array}$ \\
\hline $\begin{array}{l}\text { Religion } \\
\text { Muslim } \\
\text { Buddhist } \\
\text { Christian } \\
\text { Hinduism } \\
\text { No religion } \\
\text { Total } \\
\end{array}$ & $\begin{array}{l}1032 \\
532 \\
111 \\
69 \\
28 \\
1772 \\
\end{array}$ & $\begin{array}{l}58.2 \\
30.0 \\
6.3 \\
3.9 \\
1.6 \\
100.0\end{array}$ \\
\hline $\begin{array}{l}\text { Marital Status } \\
\text { Single } \\
\text { Married } \\
\text { Total } \\
\end{array}$ & $\begin{array}{l}1644 \\
129 \\
1773 \\
\end{array}$ & $\begin{array}{l}92.7 \\
7.3 \\
100.0\end{array}$ \\
\hline $\begin{array}{l}\text { Study Level of Students } \\
\text { Diploma } \\
\text { Bachelor } \\
\text { Master } \\
\text { PhD } \\
\text { Others } \\
\text { Total }\end{array}$ & $\begin{array}{l}28 \\
1500 \\
158 \\
85 \\
2 \\
1773 \\
\end{array}$ & $\begin{array}{l}1.6 \\
84.6 \\
8.9 \\
4.8 \\
0.1 \\
100.0\end{array}$ \\
\hline $\begin{array}{l}\text { Monthly Family income (RM) } \\
<1000 \\
1000-1999 \\
2000-2999 \\
\geq 3000 \\
\text { Information Not Available } \\
\text { Total }\end{array}$ & $\begin{array}{l}437 \\
463 \\
302 \\
414 \\
146 \\
1762\end{array}$ & $\begin{array}{l}24.8 \\
26.3 \\
17.1 \\
23.5 \\
8.3 \\
100.0\end{array}$ \\
\hline
\end{tabular}


Table 2. Attitude towards HIV/AIDS No the items

\begin{tabular}{|c|c|c|c|c|c|}
\hline \multirow[t]{2}{*}{ Item } & \multicolumn{5}{|c|}{ Frequency $(\%)$} \\
\hline & $\begin{array}{l}\text { Strongly } \\
\text { disagree }\end{array}$ & Disagree & Undecided & Agree & $\begin{array}{l}\text { Strongly } \\
\text { agree }\end{array}$ \\
\hline $\begin{array}{l}\text { i. If a relative of yours became sick } \\
\text { with HIV, you would be willing to } \\
\text { care for him/her in your own house. }\end{array}$ & $57(3.2)$ & $126(7.2)$ & $823(46.7)$ & $637(36.2)$ & $119(6.8)$ \\
\hline $\begin{array}{l}\text { ii. If a teacher has HIV, he/she } \\
\text { should be allowed to continue } \\
\text { teaching in school }\end{array}$ & $133(7.5)$ & $256(14.5)$ & $357(20.2)$ & $827(46.9)$ & $190(10.8)$ \\
\hline $\begin{array}{l}\text { iii. A child who is infected with } \\
\text { HIV can go to a normal school }\end{array}$ & $58(3.3)$ & $164(9.3)$ & $241(13.7)$ & $893(50.7)$ & $406(23.0)$ \\
\hline $\begin{array}{l}\text { iv. If a member of your family is } \\
\text { infected with HIV, you would keep } \\
\text { it secret. }\end{array}$ & $86(4.9)$ & $257(14.6)$ & $572(32.5)$ & $595(33.8)$ & $252(14.3)$ \\
\hline $\begin{array}{l}\text { v. Pre-marital testing for HIV } \\
\text { should be compulsory before getting } \\
\text { married. }\end{array}$ & $27(1.5)$ & $18(1.0)$ & $77(4.4)$ & $416(23.6)$ & $1223(69.4)$ \\
\hline $\begin{array}{l}\text { vi. Pre-marital testing for HIV can } \\
\text { protect men and women from HIV } \\
\text { infection. }\end{array}$ & $33(1.9)$ & $38(2.2)$ & $77(4.4)$ & $459(26.1)$ & $1153(65.5)$ \\
\hline $\begin{array}{l}\text { vii. There should be employment } \\
\text { opportunity for HIV infected people }\end{array}$ & $20(1.1)$ & $44(2.5)$ & $256(14.5)$ & $913(51.9)$ & $527(29.9)$ \\
\hline
\end{tabular}

Table 3. Multiple linear regression analysis showing factors associated with Attitude related to HIV/AIDS

\begin{tabular}{|l|c|c|c|c|c|c|}
\hline Models & Unstandardized Coefficients $\beta$ & Std. Error & $t$ & Sig. & \multicolumn{3}{|l|}{$95 \%$ Confidence Interval for $\beta$} \\
\hline (Constant) & 21.715 & 0.992 & 21.900 & 0.000 & 19.770 & 23.660 \\
\hline Knowledge & 0.144 & 0.014 & 10.300 & 0.000 & 0.117 & 0.172 \\
\hline Age & 0.009 & 0.026 & 0.361 & 0.718 & -0.042 & 0.060 \\
\hline Gender & 0.102 & 0.151 & 0.670 & 0.503 & -0.196 & 0.399 \\
\hline Marital Status & -0.775 & 0.430 & -1.803 & 0.072 & -1.618 & 0.068 \\
\hline Ethnicity & & & & & & \\
\hline Malay & -0.319 & 0.540 & -0.590 & 0.555 & -1.377 & 0.740 \\
\hline Chinese & -0.292 & 0.536 & -0.546 & 0.585 & -1.344 & 0.759 \\
\hline Indian & 0.790 & 0.792 & 0.997 & 0.319 & -0.764 & 2.344 \\
\hline Bumiputra & -0.060 & 0.632 & -0.094 & 0.925 & -1.299 & 1.180 \\
\hline Sabah/Sarawak & & & & & & 2 \\
\hline
\end{tabular}

